\title{
Cost-effectiveness of minimally invasive sacroiliac joint fusion
}

This article was published in the following Dove Press journal:

ClinicoEconomics and Outcomes Research

18 December 2015

Number of times this article has been viewed

\section{Daniel J Cher' \\ Melissa A Frasco ${ }^{2}$ \\ Renée JG Arnold 2,3 \\ David W Polly 4,5}

'Clinical Affairs, SI-BONE, Inc., San Jose, CA, USA; ${ }^{2}$ Division of Health Economics and Outcomes Research, Quorum Consulting, Inc., San Francisco, CA, USA; ${ }^{3}$ Department of Preventive Medicine, Icahn School of Medicine at Mount Sinai, New York, NY, USA; ${ }^{4}$ Department of Orthopaedic Surgery, University of Minnesota, Minneapolis, MN, USA; ${ }^{5}$ Department of Neurosurgery, University of Minnesota, Minneapolis, MN, USA
Correspondence: Daniel J Cher SI-BONE, Inc., 3055 Olin Avenue, Suite 2200, San Jose, CA 95128 , USA $\mathrm{Tel}+\mathrm{I} 6502695763$

Fax +l 8882434502

Email dcher@si-bone.com
Background: Sacroiliac joint (SIJ) disorders are common in patients with chronic lower back pain. Minimally invasive surgical options have been shown to be effective for the treatment of chronic SIJ dysfunction.

Objective: To determine the cost-effectiveness of minimally invasive SIJ fusion.

Methods: Data from two prospective, multicenter, clinical trials were used to inform a Markov process cost-utility model to evaluate cumulative 5-year health quality and costs after minimally invasive SIJ fusion using triangular titanium implants or non-surgical treatment. The analysis was performed from a third-party perspective. The model specifically incorporated variation in resource utilization observed in the randomized trial. Multiple one-way and probabilistic sensitivity analyses were performed.

Results: SIJ fusion was associated with a gain of approximately 0.74 quality-adjusted life years (QALYs) at a cost of US\$13,313 per QALY gained. In multiple one-way sensitivity analyses all scenarios resulted in an incremental cost-effectiveness ratio (ICER) $<\$ 26,000 /$ QALY. Probabilistic analyses showed a high degree of certainty that the maximum ICER for SIJ fusion was less than commonly selected thresholds for acceptability (mean ICER $=\$ 13,687,95 \%$ confidence interval \$5,162-\$28,085). SIJ fusion provided potential cost savings per QALY gained compared to non-surgical treatment after a treatment horizon of greater than 13 years.

Conclusion: Compared to traditional non-surgical treatments, SIJ fusion is a cost-effective, and, in the long term, cost-saving strategy for the treatment of SIJ dysfunction due to degenerative sacroiliitis or SIJ disruption.

Keywords: cost-effectiveness analysis, degenerative sacroiliitis, minimally invasive surgery, sacroiliac joint arthrodesis, sacroiliac joint disruptions, sacroiliac joint dysfunction, spine surgery

\section{Introduction}

Chronic low back pain is a major cause of disability worldwide, with an estimated 83 million well-years of life lost every year due to ill health, disability or early death. ${ }^{1}$ Low back pain is more burdensome than many other highly impactful conditions, such as cancer and COPD and is the sixth most common cause of decrements in global disability-adjusted life years. ${ }^{2}$ In highly developed countries, low back pain is in the top three causes of years with disability and the disutility of chronic low back pain has been rated as high in most countries. ${ }^{2}$

Despite recognition in the early 1900s that it can be a cause of chronic low back pain and disability, ${ }^{3}$ the sacroiliac joint (SIJ) remains a poorly recognized pain generator. Pain emanating from the SIJ is common, explaining up to $15 \%-25 \%$ of chronic low 
back pain in patients evaluated in the outpatient setting, ${ }^{4,5}$ an even higher prevalence $\left(40 \%{ }^{6}\right.$ and $\left.43 \% \%^{7}\right)$ has been reported following lumbar fusion surgeries. Several lines of evidence support the SIJ as a pain generator. Cadaveric studies show that the SIJ contains mechanoreceptors and nociceptive fibers. ${ }^{8-10}$ Blinded studies of normal volunteers show that pain elicited when probing the SIJ can be blocked with local anesthetic delivery. ${ }^{8,11}$ SIJ pain is diagnosed on the basis of history and physical examination maneuvers that stress the joint. ${ }^{12}$ In standard practice, the SIJ is confirmed as a pain generator by image-guided local anesthetic block of the joint or sacral nerve roots, as recommended by numerous practice guidelines. ${ }^{13-17}$ SIJ pain is associated with marked depression of quality of life. ${ }^{18}$ The high prevalence of SIJ conditions and corresponding poor quality of life implies that the societal burden of disease is substantial.

Non-surgical treatments for SIJ pain include medications, physical therapy, chiropractic treatment, SIJ steroid injections, and radiofrequency (RF) ablation. Published evidence for long-term pain relief following physical therapy for SIJ pain is limited. Pain relief following periarticular SIJ steroid injections was observed only temporarily in two small randomized trials. ${ }^{19,20}$ Two blinded randomized clinical trials showed that RF ablation of the sacral nerve roots was more effective than sham in relieving chronic SIJ pain. ${ }^{21-23}$ Longterm follow-up from one study showed modest 12-month pain relief. ${ }^{22}$

Until recently, surgical treatments for SIJ pain were limited. Surgical fusion of the SIJ was first reported in the $1920 s^{24}$ Since then, several single-center, retrospective case series have suggested a modest success rate for open SIJ fusion, combined with a high morbidity rate, ${ }^{25-30}$ such that open SIJ fusion is no longer commonly used. Recently, devices for minimally invasive surgery (MIS) SIJ fusion have become commercially available and the minimally invasive approach to SIJ fusion is now the most prevalent. ${ }^{31}$ Several case series have reported high rates of improvement in pain and disability after MIS SIJ fusion ${ }^{32-38}$ and results from prospective single center studies ${ }^{39-41}$ and multicenter ${ }^{42,43}$ trials have shown similar findings. In a prospective randomized controlled trial of MIS SIJ fusion vs non-surgical treatment, patients who underwent MIS SIJ fusion had markedly larger improvements in pain, disability, and quality of life compared to those who underwent non-surgical treatment. ${ }^{43,44}$ A companion multicenter prospective single arm study showed similar results. ${ }^{42}$ In a systematic review, ${ }^{45}$ long-term evidence of sustained improvement in pain and disability after MIS SIJ fusion was observed after $4^{38}$ and 5 years ${ }^{37}$ of follow-up, which lends further evidence to support the safety and effectiveness of MIS SIJ fusion. While evidence to support the safety and effectiveness of MIS SIJ fusion is growing, the cost-effectiveness of this treatment is not known. In this report, we use data derived primarily from a randomized clinical trial to analyze the incremental costeffectiveness of MIS SIJ fusion compared to non-surgical treatments in patients with chronic SIJ dysfunction due to degenerative sacroiliitis and SIJ disruptions.

\section{Methods \\ Model overview}

A Markov process model was developed to simulate 5-year US costs and health states in patients with SIJ dysfunction who are contemplating surgery. The model takes a direct cost, third-party payer perspective with a 1-month cycle length. Modeled interventions were: 1) minimally invasive SIJ fusion using triangular-shaped titanium implants placed across the SIJ (iFuse Implant System ${ }^{\circledR}$, SI-BONE, Inc., San Jose, CA, USA); and 2) non-surgical treatment for SIJ pain, consisting of physical therapy, SIJ intra-articular steroid injections and RF ablation of the SIJ. Where relevant, we followed recommendations of Ofman et al, ${ }^{46}$ which were used in a review of spine surgery-related cost-effectiveness analyses. ${ }^{47}$

A simplified version of the model is depicted in Figure 1. All patients began in the severe SIJ pain health state and underwent either SIJ fusion or non-surgical treatment. For patients receiving SIJ fusion, an additional cycle of being in the severe pain health state was modeled to represent the immediate post-surgical state and recovery.

After initial surgery, the model incorporated an event for immediate revision for patients experiencing neuropathic symptoms related to implant malposition. The health states associated with post-surgical outcomes were mild SIJ pain (indicating successful surgical response) or continued severe SIJ pain (indicating unsuccessful surgical response). As months progress, patients could either remain in the same pain health state, undergo late revision surgery, or die. To account for late loosening potentially causing SIJ pain and requiring surgical revision, this event was considered a tunnel health state. Those who received late revision surgery accrued two cycles of being in the severe pain state and then achieved the outcome of mild pain or severe pain. In the nonsurgical treatment arm, patients could remain in the severe SIJ pain health state (reflecting poor response to treatment), improve to mild SIJ pain, or die. It was assumed that after initial response to non-surgical treatment, patients either remained in the same health state or died. 


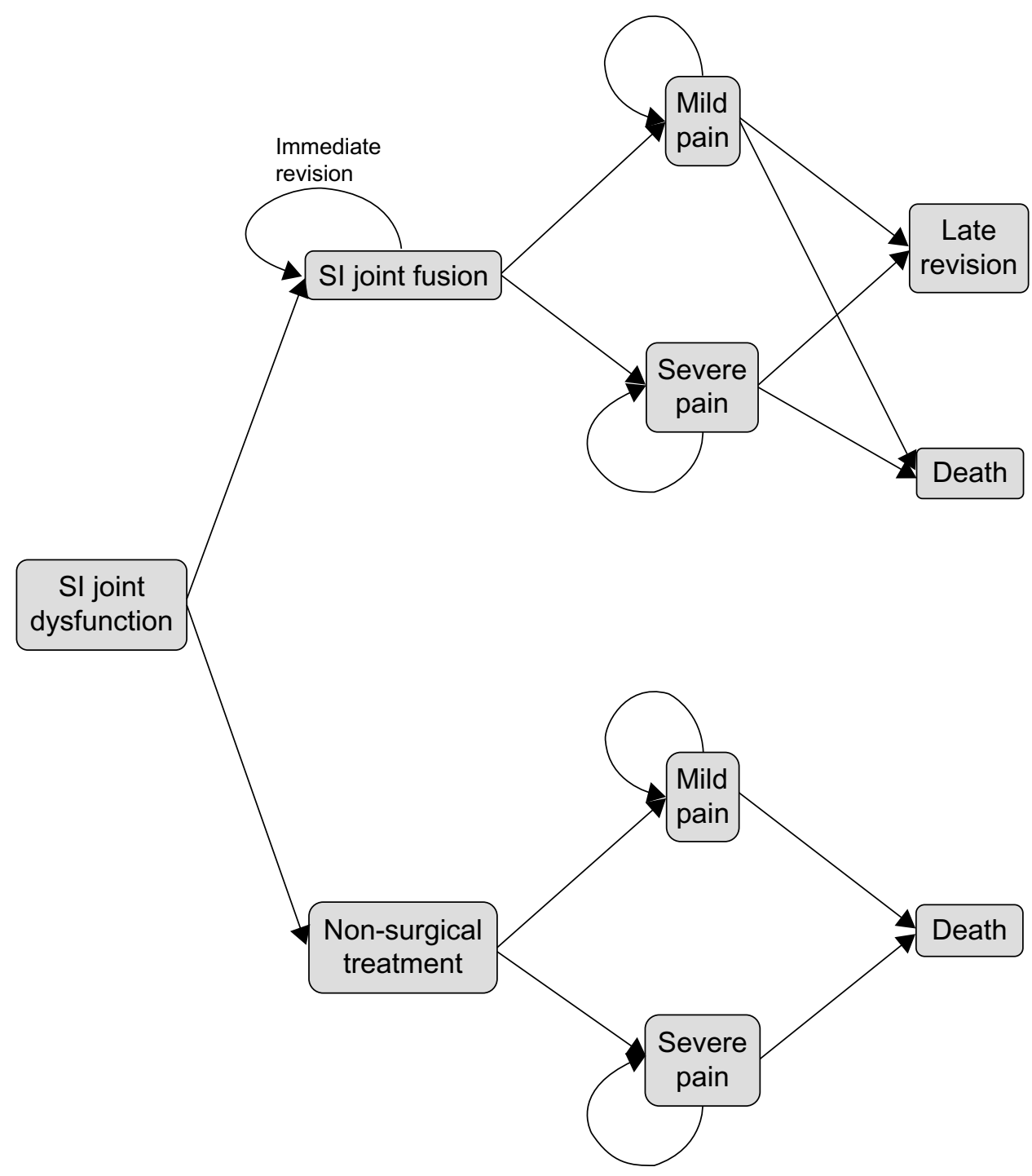

Figure I Overview of structure for the decision analysis model.

Abbreviation: SI, sacroiliac.

Based on the total time spent in the different health states, the model calculated the expected costs in US dollars and quality-adjusted life years (QALYs) associated with each treatment to calculate the relative cost-effectiveness and incremental cost-effectiveness ratio (ICER). All outcomes were discounted by $3 \%$ annually. A half-cycle correction was implemented to account for health state transitions occurring, on average, half way through each cycle. ${ }^{49}$

\section{Model inputs}

Data from two ongoing prospective clinical trials ${ }^{45,50}$ were used as primary input sources. Data from other reports of SIJ fusion and non-surgical treatment were used for other assumptions. The probability of death was assumed to be independent of health state and was based on the latest available (2009) US life table from the Centers for Disease Control and Prevention National Vital Statistics System. ${ }^{51}$

\section{Clinical inputs INSITE}

Investigation of Sacroiliac Fusion Treatment (INSITE, NCT01681004) is a prospective, multicenter, randomized controlled trial designed specifically to support this costutility analysis. ${ }^{43,44}$ INSITE participants were patients with chronic SIJ dysfunction due to degenerative sacroiliitis and SIJ disruptions who had severe SIJ pain (visual analog scale [VAS] rating $\geq 50$ on a $0-100 \mathrm{~mm}$ scale) unresponsive to at least 6 months of conservative treatment, moderate-to-severe disability (ie, an Oswestry Disability Index [ODI] score of at least 30 points), a positive Fortin finger test, SIJ pain elicited 
with at least three of five physical examination provocative maneuvers that stress the SIJ, and a marked immediate decrease in SIJ pain after fluoroscopically guided intra-articular SIJ block with local anesthetics. Patients were excluded if they had severe chronic back or hip pain due to competing hip or spine conditions, inflammatory sacroiliitis, recent major trauma, payments for disability or involvement in litigation related to SIJ or low back pain, and other reasons described in the primary clinical trial report. ${ }^{44}$ Patients were randomly assigned to receive either immediate SIJ fusion using iFuse Implant System $(n=102)$ or non-surgical treatment $(n=46)$. Non-surgical treatment consisted of medication management, SIJ-directed physical therapy, SIJ steroid injections, and RF ablation of the SIJ, delivered in a stepwise fashion according to patient needs. The non-surgical intervention in INSITE was designed to be consistent with optimal non-surgical care provided in the US and is the basis of the non-surgical treatment arm of the model reported herein. Patients in the non-surgical group could cross over to surgical treatment after the 6-month visit.

Resource utilization was collected in patients in both arms at each follow-up visit; this included the delivery of both trialrequired interventions and any additional, non-trial related pre-specified SIJ health care interventions subjects received since the last study visit, namely additional SIJ surgeries (eg, revision surgery, see "Probability of revision after MIS SIJ fusion"), SIJ steroid injections or other interventions to address SIJ pain, physical therapy beyond that specified by the protocol, and radiographic tests (magnetic resonance imaging, computed tomography, X-ray) related to adverse events or continued pain. Self-rated SIJ pain and validated quality of life assessments, including the 36-item Short Form Health Survey (SF-36) ${ }^{52}$ and EuroQOL Research Foundation (EQ-5D), ${ }^{50}$ were used to estimate health state utilities at baseline, 6 months, and 12 months. All sites obtained informed consent from participating patients prior to enrollment using study-specific consent forms approved by local or regional institutional review boards.

\section{SIFI}

Sacroiliac Joint Fusion with iFuse Implant System (SIFI) is a prospective, multicenter, single-arm clinical trial $(n=172)$ with the same eligibility criteria as INSITE. ${ }^{42}$ Similar to INSITE, VAS SIJ pain, ODI, SF-36, and EQ-5D assessments were measured at baseline and at similar structured time points in follow-up. Although SIFI did not include a randomized control group and did not capture health care resource utilization related to the SIJ, SIFI was otherwise identical in design to INSITE.

\section{Probabilities of success for MIS SIJ fusion and non-surgical treatment groups}

The proportion of patients achieving an adequate pain response to MIS SIJ fusion was based on data from both prospective SIJ fusion trials (INSITE and SIFI). In INSITE, patients randomized to SIJ fusion achieved a mean improvement from baseline in VAS SIJ pain of 52 and 54 points at 6 and 12 months, respectively (Figure S1). Pain improvements ${ }^{43}$ were very similar in SIFI at 50 and 49 points, respectively. Successful response to MIS SIJ fusion, defined as an improvement in VAS SIJ pain of at least $20 \mathrm{~mm},{ }^{52}$ occurred in $82 \%$ of surgically treated subjects in both studies at both 6 and 12 months. Random effects meta-analysis (performed with the metafor ${ }^{53} \mathrm{R}$ package) was used to combine the two trials; the meta-analytic success rate estimate was $82.2 \%$ (95\% confidence interval [CI] 77.7\%-86.8\%) and 81.7 (77.0\%-86.4\%) at 6 and 12 months, respectively. We therefore assumed a response rate to MIS SIJ fusion of $82 \%$ (range $77 \%-87 \%$, Table 1). In contrast, only $27 \%$ of INSITE subjects ( $95 \%$ CI $15.0 \%-42.8 \%$ ) assigned to non-surgical treatment showed adequate pain responses at 6 months. This value and range was taken as the probability of success for non-surgical treatment in the Markov model. Although mean pain and ODI reductions after non-surgical treatment peaked at month 3 and had slightly dissipated by month 6 , patients who achieved a favorable response to non-surgical treatment initially were assumed to remain in the same health state (good response/ mild pain) throughout follow-up.

\section{Probability of revision after MIS SIJ fusion}

Surgical revision is an important event in terms of both patient quality of life and health care costs. While revision after lumbar fusion surgery is common $(10 \%-14 \%$ at 4 years $),{ }^{54}$ surgical revision after minimally invasive SIJ surgery appears to be less common. Revisions can occur early as a result of immediate postoperative pain from implant malposition and L5-S1 nerve root irritation. Revision may also occur due to late recurrence of SIJ pain, possibly associated with implant loosening. The surgical revision rate after primary SIJ fusion surgery was estimated from inventory ( $>11,000$ US cases) and complaints databases (postmarketing surveillance) managed by SI-BONE using Kaplan-Meier survival curve analysis. Total revision rates at year 4 were $3.5 \%$ and there was evidence of decreasing 1-year revision rates over time. We therefore assumed a cumulative 1-year rate of $1 \%$ and a cumulative 4-year rate of $3.5 \%$ (Table 1). Patients undergoing 
Table I Inputs for event probabilities and utility weights for health states

\begin{tabular}{|c|c|c|c|c|}
\hline & $\begin{array}{l}\text { Base } \\
\text { case }\end{array}$ & $\begin{array}{l}\text { Range for } \\
\text { sensitivity analyses }\end{array}$ & $\begin{array}{l}\text { Distribution for } \\
\text { PSA }\end{array}$ & Sources \\
\hline \multicolumn{5}{|l|}{ Probabilities } \\
\hline \multicolumn{5}{|l|}{ SIJ fusion surgery } \\
\hline Successful response to initial surgery or early revision & 0.82 & $0.77-0.87$ & $\mathrm{~N}(0.82,0.025)^{*}$ & INSITE $^{\mathrm{a}}$ SIFI ${ }^{\mathrm{b}}$ \\
\hline Immediate revision after initial SIJ fusion & 0.01 & $0.005-0.02$ & Beta $(0.01,0.003)$ & INSITE, SIFI, Postmarketing surveillance \\
\hline Yearly late revision for symptom recurrence & 0.01 & $0.005-0.015$ & Beta $(0.01,0.002)$ & Postmarketing surveillance \\
\hline Successful response to late revision surgery & 0.5 & $0.40-0.70$ & Uni $(0.3,0.7)$ & Expert opinion \\
\hline \multicolumn{5}{|l|}{ Non-surgical treatment } \\
\hline Successful response & 0.27 & $0.15-0.43$ & Beta $(0.27,0.066)$ & INSITE \\
\hline \multicolumn{5}{|l|}{ Utilities for each health state } \\
\hline Mild pain (good response) & 0.77 & $0.75-0.95$ & Beta $(0.76,0.02)$ & INSITE, SIFI \\
\hline Severe pain (poor response) & 0.45 & $0.40-0.60$ & Beta $(0.45,0.02)$ & INSITE, SIFI \\
\hline \multicolumn{5}{|l|}{ Patient population assumptions } \\
\hline Age of patient (in years) & 50 & $40-70$ & NA & INSITE, SIFI \\
\hline Time horizon (in years) & 5 & $2-15$ & NA & NA \\
\hline
\end{tabular}

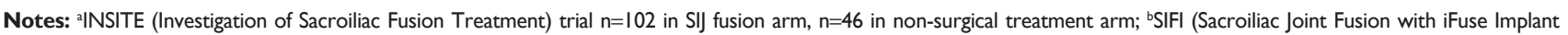
System) trial $n=172$, all of whom underwent SIJ fusion. ${ }^{*} \mathrm{~N}=$ normal distribution (mean, SD); Beta = beta distribution (listed are mean, SD); Uni = uniform distribution (min, max). Abbreviations: SIJ, sacroiliac joint; PSA, probabilistic sensitivity analysis; SD, standard deviation; NA, not applicable.

early revision surgery accrued 1 month of being in the severe SIJ pain health state. Based on expert opinion, response rates after early revision surgery were assumed to be the same as after initial surgery, and response rates after late revision surgery were assumed to be lower at $50 \%$. Patients in the mild pain health state who undergo late revision surgery accrued 2 months of being in the severe SIJ pain health state.

Because the Markov model was on a monthly basis, all yearly probability values derived from literature or other sources listed in Table 1 were converted to monthly values using the formula:

$$
\mathrm{p}_{\mathrm{m}}=1-\left(1-\mathrm{p}_{\mathrm{y}}\right)^{1 / 12}
$$

where $\mathrm{p}_{\mathrm{m}}$ is a monthly probability and $\mathrm{p}_{\mathrm{y}}$ is a yearly probability.

\section{Utility measurements}

The impact of SIJ pain and its treatment on health state utility was measured during the trials. Specifically, EQ-5D time trade-off (TTO) health state utility values assessed at baseline, and 6 and 12 months after treatment were used as model inputs. This approach has been used for other costeffectiveness analyses of spine interventions. ${ }^{55}$

At baseline, health state utility as assessed by both EQ-5D and SF-6D were substantially depressed, indicating a high burden of pain. ${ }^{18}$ In INSITE, EQ-5D TTO index was 0.45 prior to randomization. Amongst successful responders to treatment (subjects with $\geq 20 \mathrm{~mm}$ improvement in VAS SIJ pain after treatment), EQ-5D TTO index improved to $0.77(P<0.0001)$. For those who did not have successful pain responses (ie, $<20 \mathrm{~mm}$ improvement on VAS SIJ pain), the 6-month TTO index was 0.46 , which was similar to the utility value at baseline $(0.45)$ and consistent with the lack of improvement in pain. Therefore, health state utilities for the mild pain health state (positive response to treatment) and the severe pain health state (inadequate response to treatment) were assigned as 0.77 and 0.45 , respectively (Table 1 ).

\section{Utilization of health care resources and cost inputs}

Resource utilization was based on data specifically collected in INSITE using a indirectcost-accounting method. Currency in this paper is presented as US dollars. At each visit, subjects were queried regarding the occurrence of any SIJ-directed resource utilization since the last visit that was either required by the study protocol or was outside of the protocol. Based on these data, bootstrap methods were utilized to calculate the probability and variance of receipt of each health care resource across the study arms. In the SIJ fusion group, health care resources utilized included the frequency of bilateral SIJ fusion $(25 \%)$, the number of postoperative physical therapy rehabilitation sessions (mean $=9$ sessions per subject) and non-trial-related costs of workup and treatment (mean $=\$ 250$ per subject). Costs of workup included brief hospitalizations for pain control and computed tomography scans to evaluate the SIJ after a fall. In the non-surgical treatment group, interventions included number of physical therapy sessions ( mean $=13$ per subject), number of SIJ steroid injections (mean $=0.87$ per subject), number of RF ablation (mean $=0.48$ per subject) 
and non-trial-related costs of workup and treatment for adverse events or additional physical therapy (mean $=\$ 136$ per subject). Costs of workup included additional physical therapy prescribed by the physician or evaluations for residual pain after an RF ablation. After 6 months of nonsurgical treatment, we assumed that health care resource utilization for SIJ pain decreased by $50 \%$. This is a conservative assumption, given that studies have shown that non-surgical treatment of SIJ pain has persistent yearly costs, presumably to maintain clinical response. ${ }^{56,57}$

Since the model's perspective was from the third-party payer, only direct medical costs related to SIJ-related health care interventions were included. Total costs for each treatment arm were calculated as the sum-product of the mean frequency of utilizing resources and the national average payments for Medicare inpatient prospective payment system, hospital outpatient prospective payment system, and physician fee schedule Final Rule 2015. Given that SIJ fusion and other SIJ-directed procedures can occur in both the inpatient and outpatient setting, weighted averages were calculated for procedures performed in multiple settings of care. Variation in the likelihood of additional health care utilization (derived from INSITE) as well as health care costs were assumed to be $\pm 20 \%$ of base case assumptions. These variations were included in sensitivity analyses. Resource utilization, costs, and inputs for sensitivity analyses are described for both treatment arms in Table 2.

\section{Base case analysis and sensitivity analysis}

The decision analytic Markov model was programmed and analyzed using TreeAge Pro 2015 (TreeAge Software, Inc., Williamstown, MA, USA). ${ }^{58}$ The model estimates ICER during a 5-year follow-up period after MIS SIJ fusion vs non-surgical treatment. ICERs were calculated as the difference in cumulative discounted total direct costs of SIJ fusion and non-surgical treatments divided by the difference in cumulative discounted QALYs. The 5-year period was selected to be consistent with a recently published systematic review and meta-analysis on longer term data. ${ }^{45}$ Multiple one-way sensitivity analyses using ranges listed in Table 1 and Table 2 were conducted to test the robustness of the baseline results. The base case model duration was 5 years; however, we also explored models from 2 to 15 years. A probabilistic sensitivity analysis (PSA) was conducted using Monte Carlo simulation with 5,000 iterations to allow all variables to vary simultaneously. For the PSA, key variables were assigned continuous distributions using either uniform distributions, normal distributions or beta

Table 2 Inputs for cost and resource utilization

\begin{tabular}{|c|c|c|c|}
\hline Cost and utilization estimates & $\begin{array}{l}\text { Base } \\
\text { case }\end{array}$ & $\begin{array}{l}\text { Range for } \\
\text { sensitivity analyses }\end{array}$ & Source \\
\hline \multicolumn{4}{|l|}{ SIJ fusion surgery, unit costs } \\
\hline \multirow[t]{3}{*}{ Unilateral SIJ fusion/revision surgery } & $\$ 13,636^{*}$ & $\$ 10,000-\$ 18,000$ & MS-DRG 460, spinal fusion except cervical without \\
\hline & & & $\operatorname{MCC}(\$ 21,596)$ \\
\hline & & & CPT 27279, APC for SIJ fusion $(\$ 10,224)$ \\
\hline Percentage of patients requiring bilateral SIJ fusion & 0.25 & $0.1-0.35^{\#}$ & Investigation of Sacroiliac Fusion Treatment (INSITE) trial ${ }^{3}$ \\
\hline Physician payment & $\$ 574$ & $\$ 459-\$ 689 * *$ & CPT 27279 \\
\hline Anesthesia ( 4 base units +4 time units) & $\$ 180$ & $\$ 144-\$ 216^{* *}$ & CPT 01160 \\
\hline Postoperative rehabilitation per session & $\$ 105$ & $\$ 84-\$ 126 * *$ & CPT $9700 \mathrm{I}$ and CPT 97140 \\
\hline Sessions of postoperative rehabilitation & 9 & $7.2-10.8^{\#}$ & INSITE trial \\
\hline Cost for non-trial-related workup & $\$ 1,000$ & $\$ 800-\$ 1,200 * *$ & Expert opinion \\
\hline Total cost & $\$ 19,456$ & & \\
\hline \multicolumn{4}{|l|}{ Non-surgical treatment, unit costs } \\
\hline Physical therapy per session & $\$ 105$ & $\$ 84-\$ 126^{* *}$ & CPT $9700 \mathrm{I}$ and CPT $97 \mathrm{I} 40$ \\
\hline Sessions of physical therapy & 13 & $10-16^{\#}$ & INSITE trial \\
\hline SIJ steroid injection (injection for SIJ, anesthetic/ & $\$ 462^{\|}$ & $\$ 370-\$ 554^{* *}$ & CPT 27096 (injection for SIJ) \\
\hline steroid, with image guidance) & & & G0260 \\
\hline Number of SIJ steroid injections per patient in 6 mo & 0.87 & $0.6-1.1^{\#}$ & INSITE trial \\
\hline Radiofrequency (RF) ablation & $\$ 1,06 I^{\prime \prime}$ & $\$ 848-\$ 1,273 * *$ & CPT 64635 \\
\hline Number of RF ablations per patients in 6 mo & 0.48 & $0.3-0.6^{\#}$ & INSITE trial \\
\hline Costs for non-trial-related workup & $\$ 166$ & $\$ 0-\$ 500$ & Expert opinion \\
\hline Total cost & $\$ 2,446$ & & \\
\hline
\end{tabular}

Notes: *Assumes $30 \%$ inpatient, $70 \%$ outpatient; ** $\pm 20 \%$ of base case; ${ }^{*}$ distribution derived by bootstrap methods from trial data; "lassumes $50 \%$ outpatient facility, $50 \%$ physician office. Currency is presented as US dollars.

Abbreviations: SIJ, sacroiliac joint; mo, months; MS-DRG, Medicare Severity Diagnosis Related Groups; MCC, major complications or comorbidities; CPT, Current Procedural Terminology; APC, Ambulatory Payment Classifications. 
distributions (for probability parameters), with variances listed in Tables 1 and 2. The probability of cost-effectiveness as a function of various selected thresholds was calculated as per Fenwick et al. ${ }^{59}$ The $95 \%$ confidence interval for the bivariate distribution of costs and QALYs estimated in the PSA was calculated using $2 \mathrm{~d}$ kernel estimates ( $\mathrm{kde} 2 \mathrm{~d}$ from the MASS R library). ${ }^{60}$

\section{Results \\ Base case results}

The economic evaluation of MIS SIJ fusion using the iFuse Implant System relative to non-surgical treatment is presented in Table 3. The average 5-year total cost per patient who underwent SIJ fusion was $\$ 22,468$. The incremental cost of SIJ fusion relative to non-surgical treatment was $\$ 9,833$ and the incremental QALY gain was 0.74 years. The corresponding ICER was \$13,313 per QALY gained.

\section{Sensitivity analysis}

Multiple one-way sensitivity analyses were conducted for both QALYs and costs. QALYs were most sensitive to variance in model duration, the utility of severe and mild SIJ pain, and the probability of success response for each treatment (Figure S2). QALYs were not sensitive to discount rate, age at start or late surgical revision rates, including a revision rate as high as $7 \%$ (results not shown). With increasing model time horizon, the cumulative difference in QALYs grew. Cumulative costs were most sensitive to model duration, the cost of SIJ fusion surgery, the probability of bilateral surgery, and the number of physical therapy sessions in nonsurgical treatment (Figure S3). ICERs were most sensitive to the utility of severe pain, model duration, and the success rate for non-surgical treatment (Figure 2). Using the 5-year time horizon, ICERs $<\sim \$ 26,000 /$ QALY were estimated in all one-way sensitivity analyses (Figure 2). With increasing model time horizon, the differences in cost decreased, with ICERs of $<\$ 2,300 /$ QALY at 10 years and break-even costs at approximately 13 years, at which point SIJ fusion was a

Table 3 Cost-effectiveness results in base case analysis

\begin{tabular}{llll}
\hline Treatment & $\begin{array}{l}\text { Total } \\
\text { direct } \\
\text { cost }\end{array}$ & $\begin{array}{l}\text { Quality- } \\
\text { adjusted life } \\
\text { years (QALYs) }\end{array}$ & $\begin{array}{l}\text { Incremental } \\
\text { cost-effectiveness } \\
\text { ratio (ICER) }\end{array}$ \\
\hline $\begin{array}{l}\text { Non-surgical } \\
\text { treatment }\end{array}$ & $\$ 12,635$ & 2.46 & - \\
SIJ fusion & $\$ 22,468$ & 3.20 & - \\
Incremental value & $\$ 9,833$ & 0.74 & $\$ 13,313$ \\
\hline
\end{tabular}

Note: Currency is presented as US dollars.

Abbreviation: SIJ, sacroiliac joint. dominant strategy (higher QALY, lower costs). Break-even occurred at about 7 years if the costs of non-surgical treatment were raised $50 \%$.

A PSA showed a high degree of certainty that the maximum ICER for SIJ fusion was less than commonly selected thresholds for acceptability (Figure 3 ). The bivariate distribution of incremental costs and QALYs is shown in Figure S4. In fact, all simulations determined that the ICER was less than $\$ 45,000 /$ QALY and $99.5 \%$ of simulations showed values $<\$ 30,000$. The mean $(95 \% \mathrm{CI}) 5$-year cost per patient in the SIJ fusion cohort was $\$ 22,407$ (\$17,215-\$27,888) and the mean QALY was 3.20 (95\% CI 3.03-3.36). In comparison, the estimated 5-year mean cost of non-surgical treatment was $\$ 12,615(95 \%$ CI \$10,336-\$15,065) and the mean QALY was 2.46 (95\% CI 2.24-2.70). The mean ICER was $\$ 13,687$ per QALY gained (95\% CI \$5,162-\$28,085).

\section{Discussion}

We performed a cost-effectiveness analysis using quality of life and health care utilization findings from a prospective randomized controlled trial of minimally invasive SIJ fusion vs non-surgical treatment. The randomized trial provided estimates of variation in health care utilization in both surgical and non-surgical treatment, including postoperative care, that could be expected in standard clinical settings. Additional data were derived from a companion independent prospective multicenter clinical trial of SIJ fusion ${ }^{42}$ as well as a systematic review. ${ }^{45}$

Minimally invasive SIJ fusion was associated with a 0.74 expected cumulative QALY gain after 5 years at an incremental cost of approximately $\$ 9,800$, resulting in an ICER of approximately $\$ 13,300 / \mathrm{Q} A L Y$. The primary model drivers for cost-effectiveness were utility values associated with severe SIJ pain, costs of the index surgery, and the probability of successful treatment with non-surgical treatment. The base case time horizon was 5 years; when the model was extended beyond 13 years, the cumulative cost curves crossed (break-even around 13 years). The long-term costs of non-surgical treatment continue to accrue because the model assumed that ongoing non-surgical interventions are required to maintain pain relief. Altogether, the model found that minimally invasive SIJ fusion using triangular titanium implants was likely to be a highly cost-effective strategy for patients with chronic SIJ dysfunction who participated in INSITE. With longer time horizons, the cost-effectiveness improved (eg, ICER of $\sim \$ 2,500 /$ QALY at 10 years).

Several devices for minimally invasive SIJ fusion are now commercially available in the US. However, the majority of 


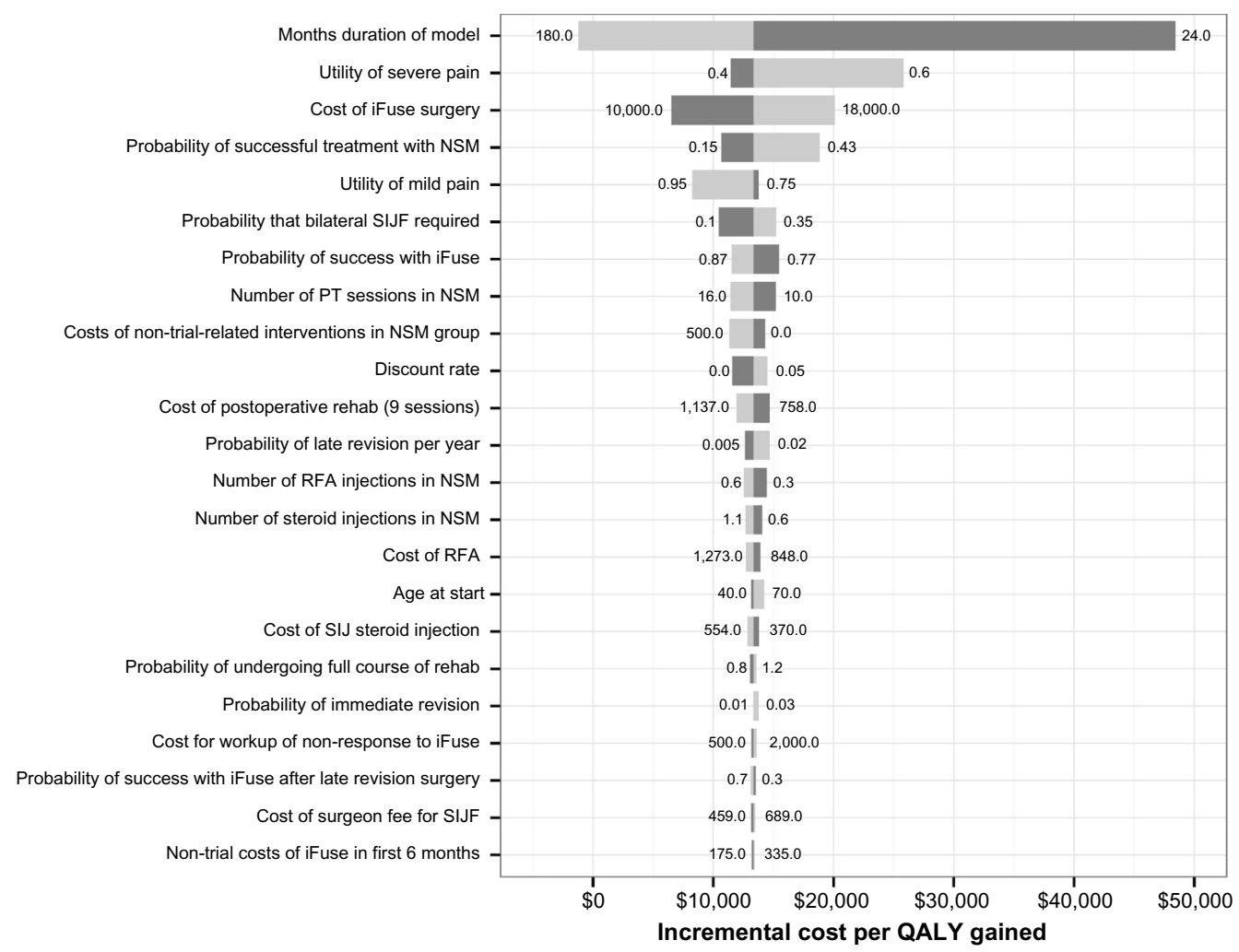

Figure 2 Tornado diagram of incremental cost-effectiveness ratio (ICER).

Notes: Numbers for each bar show the low and high assumptions for each parameter. Light gray indicates the higher assumption has a higher ICER; dark gray indicates that the lower assumption has a higher ICER. Currency is presented as US dollars.

Abbreviations: SIJF, sacroiliac joint fusion; rehab, rehabilitation; RFA, radiofrequency ablation; mo, months; QALY, quality-adjusted life years; NSM, non-surgical management; PT, physical therapy.

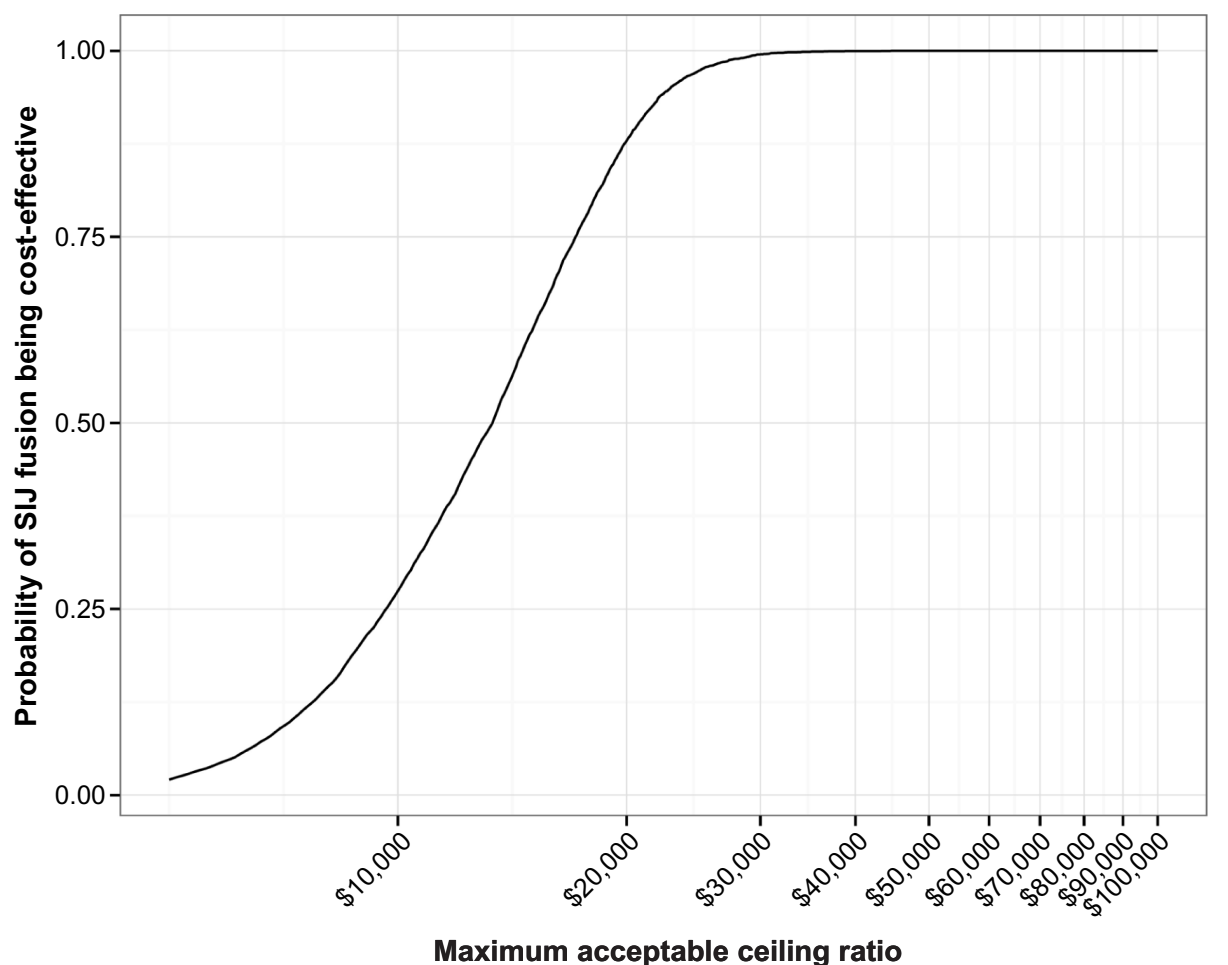

Figure 3 Cost-effectiveness acceptability curve.

Notes: The x-axis shows a range of maximum acceptable ceiling ratios; the $y$-axis shows the probability that SIJ fusion is cost effective according to the selected maximum ratio. Currency is presented as US dollars.

Abbreviation: SIJ, sacroiliac joint. 
the published literature reports use titanium porous coated implants that are triangular in cross-section; these implants are designed to stabilize the joint, prevent joint rotation, and promote long-term fusion. Published case series ${ }^{32-38}$ and comparative cohorts ${ }^{61,62}$ attest to the safety and effectiveness of the procedure but did not provide information on the economic value of the procedure. (Indeed, economic value of most neurosurgical or spine procedures is lacking. $)^{63}$

Comparing our results to those from other costeffectiveness analyses embedded within primary clinical trial data is instructive. The landmark SPORT studies, ${ }^{64-66}$ which compared surgical and non-surgical treatment for three common spine conditions, included a detailed costeffectiveness component. In patients with lumbar disc herniation, the estimated mean 2-year gain in QALYs when using surgical as opposed to non-surgical treatment was $0.21{ }^{64}$ The cost per QALY gained was $\$ 69,000$; for patients aged 65 or older the ICER decreased to $\$ 34,000$. In lumbar spinal stenosis, decompressive laminectomy provided a QALY gain over non-surgical treatment of 0.17 years at a cost of $\$ 77,000$ per QALY gained. ${ }^{65}$ In degenerative spondylolisthesis, the mean 0.23 QALY gain cost $\$ 115,000$. A 4-year update of the SPORT studies showed ICERs of $\$ 59,000$ per QALY in spinal stenosis, $\$ 64,000$ per QALY for degenerative spondylolisthesis, and \$20,000 per QALY for intervertebral disc herniation. ${ }^{66}$ These values are notably higher than those from our model. Moreover, analyses derived from SPORT may be limited by the nonrandomized nature of the comparisons resulting from massive early crossover in these studies. The SIJ cohort studied in our randomized trial may have had worse quality of life at baseline compared to subjects in SPORT, ${ }^{67}$ and the SIJ fusion procedure may be less costly than some of the spine surgeries SPORT investigated; these may have allowed more QALY improvement and less treatment costs, leading to better overall cost-effectiveness.

For patients with symptomatic single-level lumbar degenerative disc disease of at least 6 months that had failed non-operative care, use of recombinant bone morphogenetic protein-2 during a single-level instrumented posterolateral lumbar interbody fusion was reported to cost $\$ 30,000$ per QALY. ${ }^{6}$ This calculation was done without a comparator nonsurgical group, so the cost-effectiveness of this intervention relative to non-surgical treatment is not known. In patients with moderate lumbar stenosis, analysis of a randomized trial similar to INSITE showed that an interspinous spacer (X-STOP) was highly cost-effective (\$18,000 per QALY) compared to conservative care ${ }^{69}$ However, subsequent studies showing relatively high revision rates after $\mathrm{X}-\mathrm{STOP}^{70-72}$ suggest that cost-effectiveness of this intervention may not be maintained over a longer time horizon.

These comparisons with other surgical procedures in the spine suggest that SIJ fusion with titanium implants has a cost-effectiveness similar to that of hip and knee arthroplasty (ICERs approximately \$10,000 per QALY for hip arthroplasty and $\$ 12,000$ for total knee arthroplasty) ${ }^{73}$ and better than those of laminectomy for lumbar stenosis and lumbar fusion for degenerative spondylolisthesis.

Parker and McGirt described the concept of minimally clinically effective difference as the amount of improvement necessary to achieve cost effectiveness. ${ }^{74}$ In our model, the incremental cost-effectiveness of SIJ fusion was $<\$ 50,000$ per QALY provided that the success rate with SIJ fusion was at least $45 \%$. In both INSITE and SIFI, the success rate was $>80 \%$, suggesting both that the change in health observed with SIJ fusion exceeds the minimally cost-effective difference and that the likelihood of cost-effectiveness of SIJ fusion is high.

\section{Strengths and limitations}

Our model has several strengths. First, the model incorporated data directly collected from an ongoing prospective randomized trial of SIJ fusion vs non-surgical treatment over 12 months as well as data from a companion clinical trial with identical success rates. Subjects in both studies attended multiple, pre-scheduled follow-up visits, allowing for repeated assessments of success rates and quality of life. In INSITE, specific information on health care utilization required by the trial as well as additional non-trial resource use was collected. Trial data were used to calculate ranges for key variables in sensitivity analyses. The rate of surgical revision, an important outcome for any surgical procedure, was directly estimated from postmarketing surveillance systems over 5 years. Because revision rates were low, they did not have a meaningful impact on cost-effectiveness calculations. Finally, overall model results were found to be robust to changes in key parameters. PSA with wide distributional assumptions revealed that the surgical strategy was cost-effective and, in some scenarios, cost-saving, compared to non-surgical treatment.

The primary limitation of the model is the lack of economic data from prospective trials with greater than 12 months of follow-up. The 5-year time frame was selected to reflect the time frame for data available on clinical outcomes, as summarized in a recently published systematic review. ${ }^{45}$ Based on this information, we assumed that patients who did not require revision surgery maintained lasting successful response to SIJ fusion and remained in the mild pain health state. This assumption is supported by long-term SIJ fusion 
cohort studies. ${ }^{37,38}$ Given that long-term data substantiating sustained positive responses to non-surgical treatment of SIJ pain are not available, our model may be considered as conservative. Our model assumed that maintenance of pain relief in patients who respond to non-surgical treatments requires ongoing interventions (eg, ongoing physical therapy, SIJ steroid injections and/or RF ablation). This assumption is reasonable given that available non-surgical treatments for SIJ pain do not address the underlying fundamental cause of SIJ pain. The need for ongoing treatment costs is supported in a recent analysis of Medicare ${ }^{56}$ and non-Medicare ${ }^{57}$ sources describing medical expenditures for non-surgical treatment of SIJ pain that were substantially higher than the costs incurred in the cohort of non-surgical management in our model. Thus, our assumption that the intensity of non-surgical treatment after month 6 was half that expended during the first six months was conservative. Taken together, the above data suggest that our estimates of costs of non-surgical treatments were underestimated and our estimates of the cost-effectiveness of SIJ fusion may be conservative.

Our model applies only to patients with SIJ as diagnosed with the strategy used in INSITE, namely a combination of characteristic pain history, positive findings on at least three of five physical examination provocative maneuvers that stress the SIJ, and a positive diagnostic SIJ block. This diagnostic strategy is commonly used in clinical practice. Our model may also apply only to the triangular implant used in INSITE. Whether our results apply to other devices used to fuse the SIJ, such as hollow modular anchor screws, ${ }^{39-41}$ is not known.

Finally, we did not include medication use in our model. The INSITE randomized trial showed only a modest reduction in narcotic use after 6 months in those treated with MIS SIJ fusion compared to non-surgical treatment. Including these reductions in pain medication use may have resulted in somewhat improved cost-effectiveness ratios.

\section{Conclusion}

Markov modeling based on a prospective clinical trial showed minimally invasive SIJ fusion to be a highly cost-effective, and, in the long term, cost saving strategy for the treatment of SIJ dysfunction due to SIJ degeneration or disruption. The cost-effectiveness of minimally invasive SIJ fusion is similar to that of hip and knee arthroplasty.

\section{Acknowledgment}

Financial/material support: the study reported herein was sponsored by SI-BONE, Inc. (San Jose, CA). The trials on which this analysis is based were sponsored by SI-BONE.

\section{Disclosure}

Daniel J Cher is an SI-BONE employee. Renee JG Arnold and Melissa A Frasco are employees of Quorum Consulting, hired by SI-BONE to help prepare and evaluate the cost-utility model. The authors report no other conflicts of interest in this work.

\section{References}

1. Murray CJ, Vos T, Lozano R, et al. Disability-adjusted life years (DALYs) for 291 diseases and injuries in 21 regions, 1990-2010: a systematic analysis for the Global Burden of Disease Study 2010. Lancet. 2012;380(9859):2197-2223.

2. Salomon JA, Vos T, Hogan DR, et al. Common values in assessing health outcomes from disease and injury: disability weights measurement study for the Global Burden of Disease Study 2010. Lancet. 2012; 380(9859):2129-2143.

3. Smith-Petersen MN. Clinical diagnosis of common sacroiliac conditions. Am J Roentgenol Radium Ther. 1924;12:546-550.

4. Sembrano JN, Polly DW Jr. How often is low back pain not coming from the back? Spine (Phila Pa 1976). 2009;34(1):E27-E32.

5. DePalma MJ, Ketchum JM, Saullo T. What is the source of chronic low back pain and does age play a role? Pain Med. 2011;12(2):224-233.

6. Liliang PC, Lu K, Liang CL, Tsai YD, Wang KW, Chen HJ. Sacroiliac joint pain after lumbar and lumbosacral fusion: findings using dual sacroiliac joint blocks. Pain Med. 2011;12(4):565-570.

7. DePalma MJ, Ketchum JM, Saullo TR. Etiology of chronic low back pain in patients having undergone lumbar fusion. Pain Med.2011;12(5): 732-739.

8. Fortin JD, Kissling RO, O'Connor BL, Vilensky JA. Sacroiliac joint innervation and pain. Am J Orthop (Belle Mead NJ). 1999;28(12): 687-690.

9. Sakamoto N, Yamashita T, Minaki Y, et al. Mechanoreceptors in the sacroiliac joint: 45th Annual Meeting, Orthopaedic Research Society, Anaheim, California, February 1-4, 1999. Orthopaedic Research Society; 1999 .

10. Sakamoto N, Yamashita T, Takebayashi T, Sekine M, Ishii S. An electrophysiologic study of mechanoreceptors in the sacroiliac joint and adjacent tissues. Spine (Phila Pa 1976). 2001;26(20):E468-E471.

11. Dreyfuss P, Henning T, Malladi N, Goldstein B, Bogduk N. The ability of multi-site, multi-depth sacral lateral branch blocks to anesthetize the sacroiliac joint complex. Pain Med. 2009;10(4):679-688.

12. Szadek KM, van der Wurff P, van Tulder MW, Zuurmond WW, Perez RS. Diagnostic validity of criteria for sacroiliac joint pain: a systematic review. J Pain. 2009;10(4):354-368.

13. Manchikanti L, Abdi S, Atluri S, et al. An update of comprehensive evidence-based guidelines for interventional techniques in chronic spinal pain. Part II: guidance and recommendations. Pain Physician. 2013;16(2 Suppl):S49-S283.

14. Pauza KJ. Educational Guidelines for Interventional Spinal Procedures. American Academy of Physical Medicine and Rehabilitation; 2008. Available from: http://www.aapmr.org/practice/guidelines/documents/ edguidelines.pdf. Accessed November 24, 2015.

15. Bogduk N, editor. Practice Guidelines for Spinal Diagnostic and Treatment Procedures. Kentfield: International Spine Intervention Society; 2004.

16. Manchikanti L, Boswell MV, Singh V, et al. Comprehensive evidencebased guidelines for interventional techniques in the management of chronic spinal pain. Pain Physician. 2009;12(4):699-802.

17. American Society of Anesthesiologists Task Force on Chronic Pain Management, American Society of Regional Anesthesia and Pain Medicine. Practice guidelines for chronic pain management: an updated report by the American Society of Anesthesiologists Task Force on Chronic Pain Management and the American Society of Regional Anesthesia and Pain Medicine. Anesthesiology. 2010;112(4):810-833. 
18. Cher D, Polly D, Berven S. Sacroiliac Joint pain: burden of disease. Med Devices (Auckl). 2014;7:73-81.

19. Luukkainen RK, Wennerstrand PV, Kautiainen HH, Sanila MT, Asikainen EL. Efficacy of periarticular corticosteroid treatment of the sacroiliac joint in non-spondylarthropathic patients with chronic low back pain in the region of the sacroiliac joint. Clin Exp Rheumatol. 2002;20(1):52-54.

20. Luukkainen R, Nissilä M, Asikainen E, et al. Periarticular corticosteroid treatment of the sacroiliac joint in patients with seronegative spondylarthropathy. Clin Exp Rheumatol. 1999;17(1):88-90.

21. Patel N, Gross A, Brown L, Gekht G. A randomized, placebo-controlled study to assess the efficacy of lateral branch neurotomy for chronic sacroiliac joint pain. Pain Med. 2012;13(3):383-398.

22. Patel N. Twelve-Month Follow-Up of a Randomized Trial Assessing Cooled Radiofrequency Denervation as a Treatment for Sacroiliac Region Pain. Pain Pract. Epub 2015 Jan 7.

23. Cohen SP, Hurley RW, Buckenmaier CC 3rd, et al. Randomized placebocontrolled study evaluating lateral branch radiofrequency denervation for sacroiliac joint pain. Anesthesiology. 2008;109(2):279-288.

24. Smith-Petersen MN. Arthrodesis of the sacroiliac joint. A new method of approach. Journal of Bone and Joint Surgery. 1921;3:400-405.

25. McGuire RA, Chen Z, Donahoe K. Dual fibular allograft dowel technique for sacroiliac joint arthrodesis. Evid Based Spine Care J. 2012; 3(3):21-28.

26. Kibsgård TJ, Røise O, Stuge B. Pelvic joint fusion in patients with severe pelvic girdle pain - a prospective single-subject research design study. BMC Musculoskelet Disord. 2014;15:85.

27. Buchowski JM, Kebaish KM, Sinkov V, et al. Functional and radiographic outcome of sacroiliac arthrodesis for the disorders of the sacroiliac joint. Spine J. 2005;5(5):520-528; discussion 529.

28. Giannikas KA, Khan AM, Karski MT, Maxwell HA. Sacroiliac joint fusion for chronic pain: a simple technique avoiding the use of metalwork. Eur Spine J. 2004;13(3):253-256.

29. Belanger TA, Dall BE. Sacroiliac arthrodesis using a posterior midline fascial splitting approach and pedicle screw instrumentation: a new technique. J Spinal Disord. 2001;14(2):118-124.

30. Berthelot JM, Gouin F, Glemarec J, Maugars Y, Prost A. Possible use of arthrodesis for intractable sacroiliitis in spondylarthropathy: report of two cases. Spine (Phila Pa 1976). 2001;26(20):2297-2299.

31. Lorio MP, Polly DW Jr, Ninkovic I, et al. Utilization of Minimally Invasive Surgical Approach for Sacroiliac Joint Fusion in Surgeon Population of ISASS and SMISS Membership. Open Orthop J. 2014;8:1-6.

32. Rudolf L. Sacroiliac Joint Arthrodesis-MIS Technique with Titanium Implants: Report of the First 50 Patients and Outcomes. Open Orthop J. 2012;6:495-502.

33. Sachs D, Capobianco R. Minimally invasive sacroiliac joint fusion: one-year outcomes in 40 patients. Adv Orthop. 2013;2013:536128.

34. Cummings J Jr, Capobianco RA. Minimally invasive sacroiliac joint fusion: one-year outcomes in 18 patients. Ann Surg Innov Res. 2013;7(1):12.

35. Schroeder JE, Cunningham ME, Ross T, Boachie-Adjei O. Early results of sacro-iliac joint fixation following long fusion to the sacrum in adult spine deformity. HSS J. 2014;10(1):30-35.

36. Gaetani P, Miotti D, Risso A, et al. Percutaneous arthrodesis of sacroiliac joint: a pilot study. J Neurosurg Sci. 2013;57(4):297-301.

37. Rudolf L, Capobianco R. Five-year clinical and radiographic outcomes after minimally invasive sacroiliac joint fusion using triangular implants. Open Orthop J. 2014;8:375-383.

38. Vanaclocha VV, Verdu-Lopez F, Sanchez-Pardo M, et al. Minimally invasive sacroiliac joint arthrodesis: experience in a prospective series with 24 patients. J Spine. 2014;3:185.

39. Khurana A, Guha AR, Mohanty K, Ahuja S. Percutaneous fusion of the sacroiliac joint with hollow modular anchorage screws: clinical and radiological outcome. J Bone Joint Surg Br. 2009;91(5):627-631.

40. Mason LW, Chopra I, Mohanty K. The percutaneous stabilisation of the sacroiliac joint with hollow modular anchorage screws: a prospective outcome study. Eur Spine J. 2013;22(10):2325-2331.
41. Endres S, Ludwig E. Outcome of distraction interference arthrodesis of the sacroiliac joint for sacroiliac arthritis. Indian J Orthop. 2013;47(5): 437-442.

42. Whang P, Cher D, Polly D, et al. Sacroiliac joint fusion using triangular titanium implants vs non-surgical management: six-month outcomes from a prospective randomized controlled trial. Int J Spine Surg. 2015;9:6.

43. Polly DW, Cher DJ, Wine KD, et al. Randomized Controlled Trial of Minimally Invasive Sacroiliac Joint Fusion Using Triangular Titanium Implants vs Nonsurgical Management for Sacroiliac Joint Dysfunction: 12-Month Outcomes. Neurosurgery. 2015;77(5):674-697.

44. Duhon BS, Cher DJ, Wine KD, Kovalsky D, Lockstadt H. Triangular titanium implants for minimally invasive sacroiliac joint fusion: a prospective study. Global Spine J. Epub 2015 Aug 11.

45. Heiney J, Capobianco R, Cher D. Systematic review of minimally invasive sacroiliac joint fusion using a lateral transarticular approach. Int J Spine Surg. 2015;9:40.

46. Ofman JJ, Sullivan SD, Neumann PJ, et al. Examining the value and quality of health economic analyses: implications of utilizing the QHES. J Manag Care Pharm. 2003;9(1):53-61.

47. Nwachukwu BU, Schairer WW, Shifflett GD, Kellner DB, Sama AA. Cost-utility analyses in spine care: a qualitative and systematic review. Spine (Phila Pa 1976). 2015;40(1):31-40.

48. Siebert U, Alagoz O, Bayoumi AM, Jahn B, Owens DK, Cohen DJ, Kuntz KM; ISPOR-SMDM Modeling Good Research Practices Task Force. State-Transition Modeling: A Report of the ISPOR-SMDM Modeling Good Research Practices Task Force-3. Value Health. 2012:15(6):812-820.

49. Arias, E. United States life tables, 2010. National Vital Statistics Reports. 2014;63(7):1-63.

50. Ware JE Jr, Sherbourne CD. The MOS 36-item short-form health survey (SF-36). I. Conceptual framework and item selection. Med Care. 1992;30(6):473-483.

51. EuroQol Group. EuroQol - a new facility for the measurement of healthrelated quality of life. Health Policy. 1990;16(3):199-208.

52. Childs JD, Piva SR, Fritz JM. Responsiveness of the numeric pain rating scale in patients with low back pain. Spine (Phila Pa 1976). 2005; 30(11):1331-1334.

53. Viechtbauer W. Conducting meta-analyses in R with the metafor package. Journal of Statistical Software. 2010;36:1-48.

54. Martin BI, Mirza SK, Comstock BA, et al. Reoperation rates following lumbar spine surgery and the influence of spinal fusion procedures. Spine (Phila Pa 1976). 2007;32(3):382-387.

55. Lønne G, Johnsen LG, Aas E, et al. Comparing cost-effectiveness of X-stop to minimally invasive decompression in lumbar spinal stenosis: a randomized controlled trial. Spine (Phila Pa 1976). 2015;40(8):514-520.

56. Ackerman SJ, Polly DW Jr, Knight T, Holt T, Cummings J Jr. Nonoperative care to manage sacroiliac joint disruption and degenerative sacroiliitis: high costs and medical resource utilization in the United States Medicare population. J Neurosurg Spine. 2014;20(4): 354-363.

57. Ackerman SJ, Polly DW Jr, Knight T, et al. Comparison of the costs of nonoperative care to minimally invasive surgery for sacroiliac joint disruption and degenerative sacroiliitis in a United States commercial payer population: potential economic implications of a new minimally invasive technology. Clinicoecon Outcomes Res. 2014;6: 283-296.

58. TreeAge Pro 2015. R1.0. TreeAge Software, Williamstown, MA. Available from: http://www.treeage.com. Accessed November 24, 2015.

59. Fenwick E, Marshall DA, Levy AR, Nichol G. Using and interpreting cost-effectiveness acceptability curves: an example using data from a trial of management strategies for atrial fibrillation. BMC Health Serv Res. 2006;6:52.

60. Venables WN, Ripley BD. Modern Applied Statistics with S. New York: Springer-Verlag New York; 2002. 
61. Ledonio CG, Polly DW Jr, Swiontkowski MF, Cummings JT Jr. Comparative effectiveness of open versus minimally invasive sacroiliac joint fusion. Med Devices (Auckl). 2014;7:187-193.

62. Smith AG, Capobianco R, Cher D, et al. Open versus minimally invasive sacroiliac joint fusion: a multi-center comparison of perioperative measures and clinical outcomes. Ann Surg Innov Res. 2013;7(1):14.

63. Zygourakis CC, Kahn JG. Cost-effectiveness research in neurosurgery. Neurosurg Clin N Am. 2015;26(2):189-196.

64. Tosteson AN, Skinner JS, Tosteson TD, et al. The cost effectiveness of surgical versus non-operative treatment for lumbar disc herniation over two years: evidence from the Spine Patient Outcomes Research Trial (SPORT). Spine (Phila Pa 1976). 2008;33(19):2108-2115.

65. Tosteson AN, Lurie JD, Tosteson TD, et al. Surgical treatment of spinal stenosis with and without degenerative spondylolisthesis: costeffectiveness after 2 years. Ann Intern Med. 2008;149(12):845-853.

66. Tosteson AN, Tosteson TD, Lurie JD, et al. Comparative effectiveness evidence from the spine patient outcomes research trial: surgical versus nonoperative care for spinal stenosis, degenerative spondylolisthesis, and intervertebral disc herniation. Spine (Phila Pa 1976). 2011;36(24): 2061-2068.

67. Cher DJ, Reckling WC. Quality of life in preoperative patients with sacroiliac joint dysfunction is at least as depressed as in other lumbar spinal conditions. Med Devices (Auckl). 2015;8:395-403.
68. Glassman SD, Polly DW, Dimar JR, Carreon LY. The cost effectiveness of single-level instrumented posterolateral lumbar fusion at 5 years after surgery. Spine (Phila Pa 1976). 2012;37(9):769-774.

69. Skidmore G, Ackerman SJ, Bergin C, et al. Cost-effectiveness of the $\mathrm{X}-\mathrm{STOP}{ }^{\circledR}$ interspinous spacer for lumbar spinal stenosis. Spine (Phila Pa 1976). 2011;36(5):E345-E356.

70. Verhoof OJ, Bron JL, Wapstra FH, van Royen BJ. High failure rate of the interspinous distraction device (X-Stop) for the treatment of lumbar spinal stenosis caused by degenerative spondylolisthesis. Eur Spine J. 2008;17(2):188-192.

71. Tuschel A, Chavanne A, Eder C, Meissl M, Becker P, Ogon M. Implant survival analysis and failure modes of the X-Stop interspinous distraction device. Spine (Phila Pa 1976). 2013;38(21):1826-1831.

72. Lønne G, Johnsen LG, Rossvoll I, et al. Minimally invasive decompression versus $\mathrm{X}$-stop in lumbar spinal stenosis: a randomized controlled multicenter study. Spine (Phila Pa 1976). 2015;40(2):77-85.

73. Daigle ME, Weinstein AM, Katz JN, Losina E. The cost-effectiveness of total joint arthroplasty: a systematic review of published literature. Best Pract Res Clin Rheumatol. 2012;26(5):649-658.

74. Parker SL, McGirt MJ. Determination of the minimum improvement in pain, disability, and health state associated with cost-effectiveness: introduction of the concept of minimum cost-effective difference. Neurosurgery. 2015;76 Suppl 1:S64-S70. 


\section{Supplementary materials}

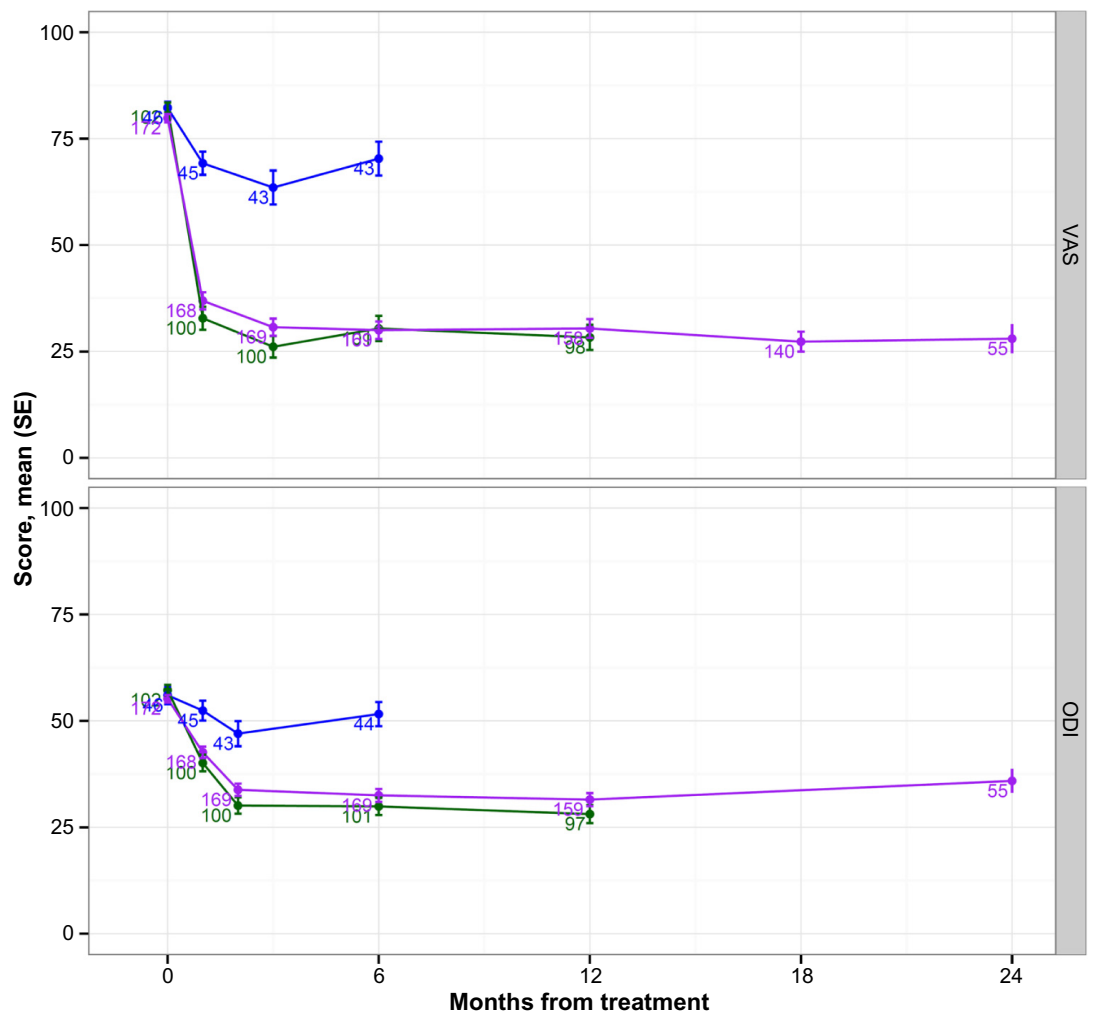

Figure SI Improvement in VAS pain in two trials.

Notes: INSITE (Investigation of Sacroiliac Fusion Treatment), a prospective trial, randomized subjects to minimally invasive surgical fusion (green) or non-surgical treatment (blue). SIFI, (Sacroiliac Joint Fusion with iFuse Implant System) a prospective single-arm trial, treated all subjects with surgical fusion (purple). Values plotted are mean \pm SE. Numbers refer to number of subjects at each time point in whom outcomes were evaluated. Both studies are ongoing. More than $80 \%$ of subjects in non-surgical arm crossed over to surgery at 6 months in INSITE.

Abbreviations: VAS, visual analog scale; SE, standard error; ODI, Oswestry Disability Index.

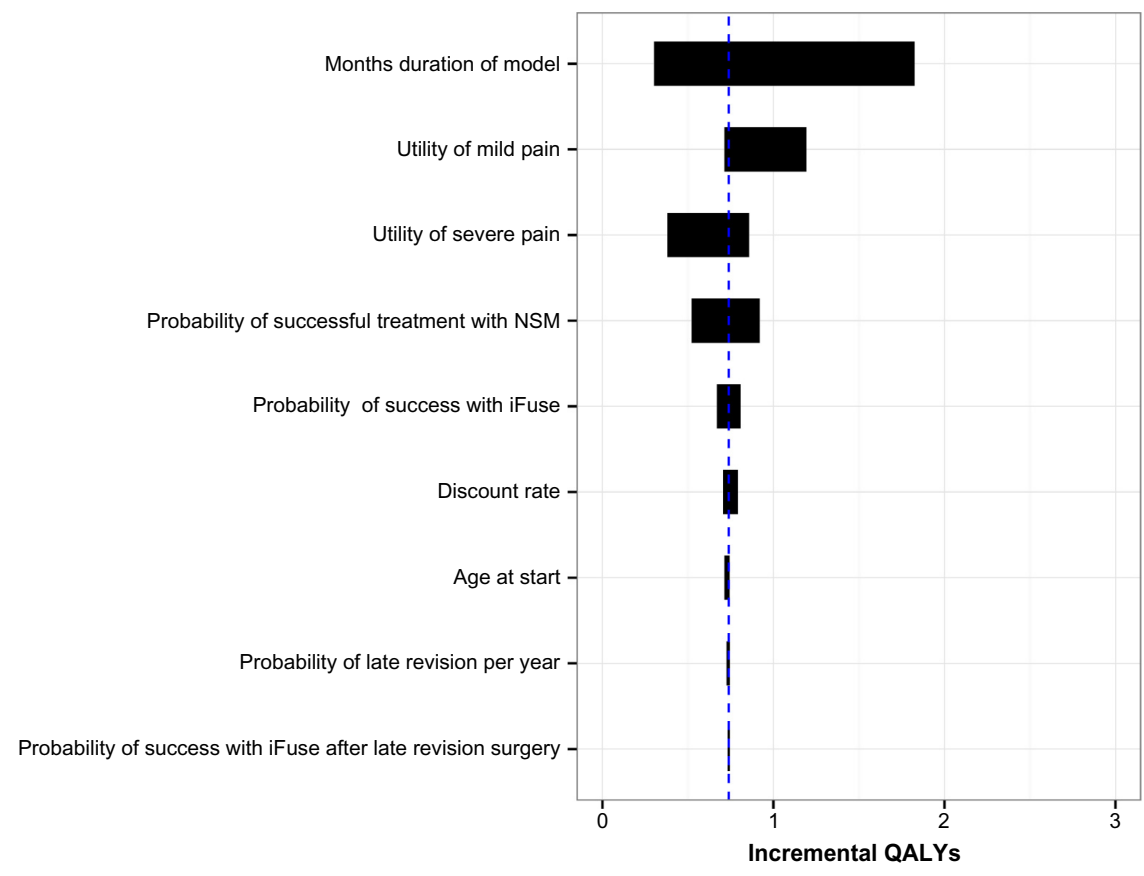

Figure S2 One-way sensitivity analysis for incremental QALYs (SIJ fusion - NSM).

Abbreviations: QALYs, quality-adjusted life years; SIJ, sacroiliac joint; NSM, non-surgical management. 


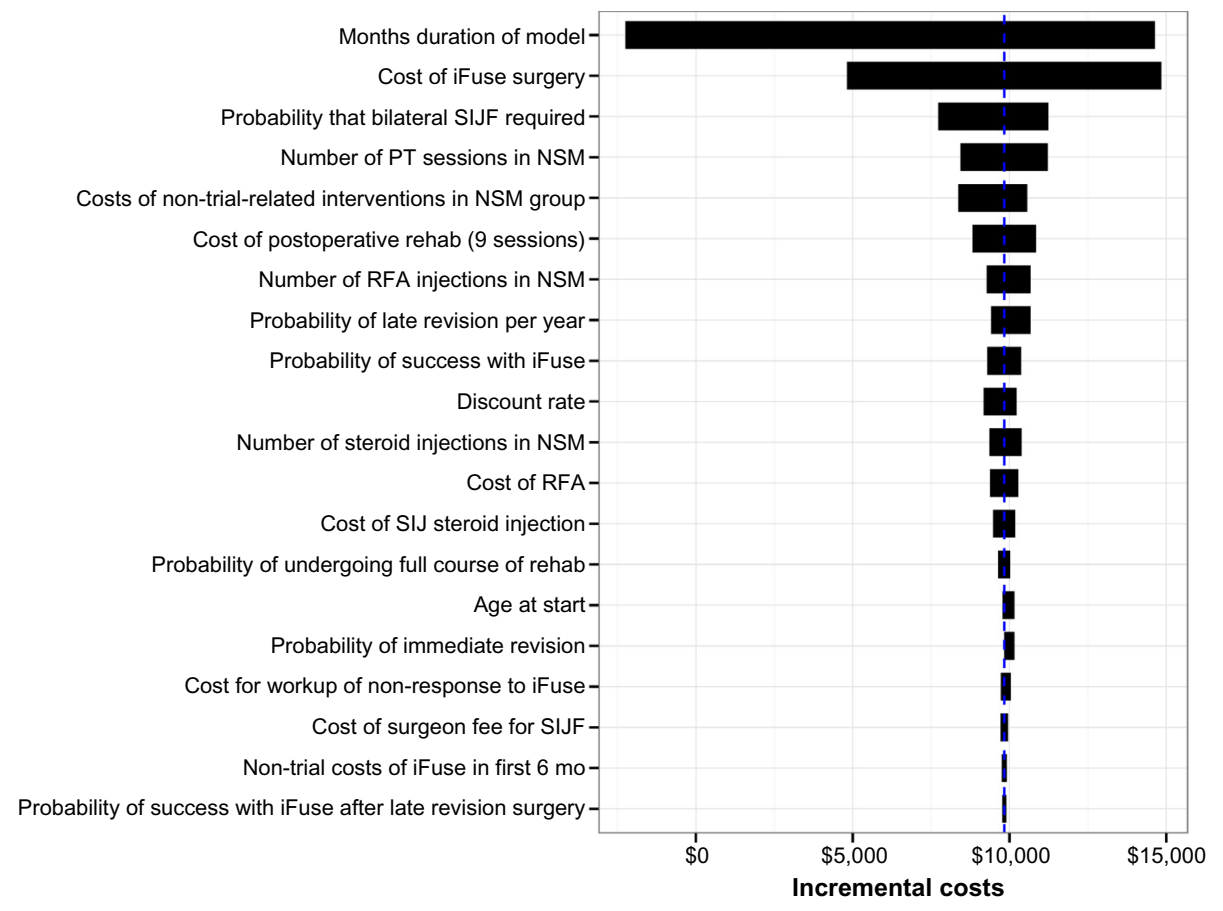

Figure S3 One-way sensitivity analysis for incremental costs (SIJF - NSM).

Abbreviations: SIJF, sacroiliac joint fusion; rehab, rehabilitation; RFA, radiofrequency ablation; mo, months; NSM, non-surgical management; PT, physical therapy.

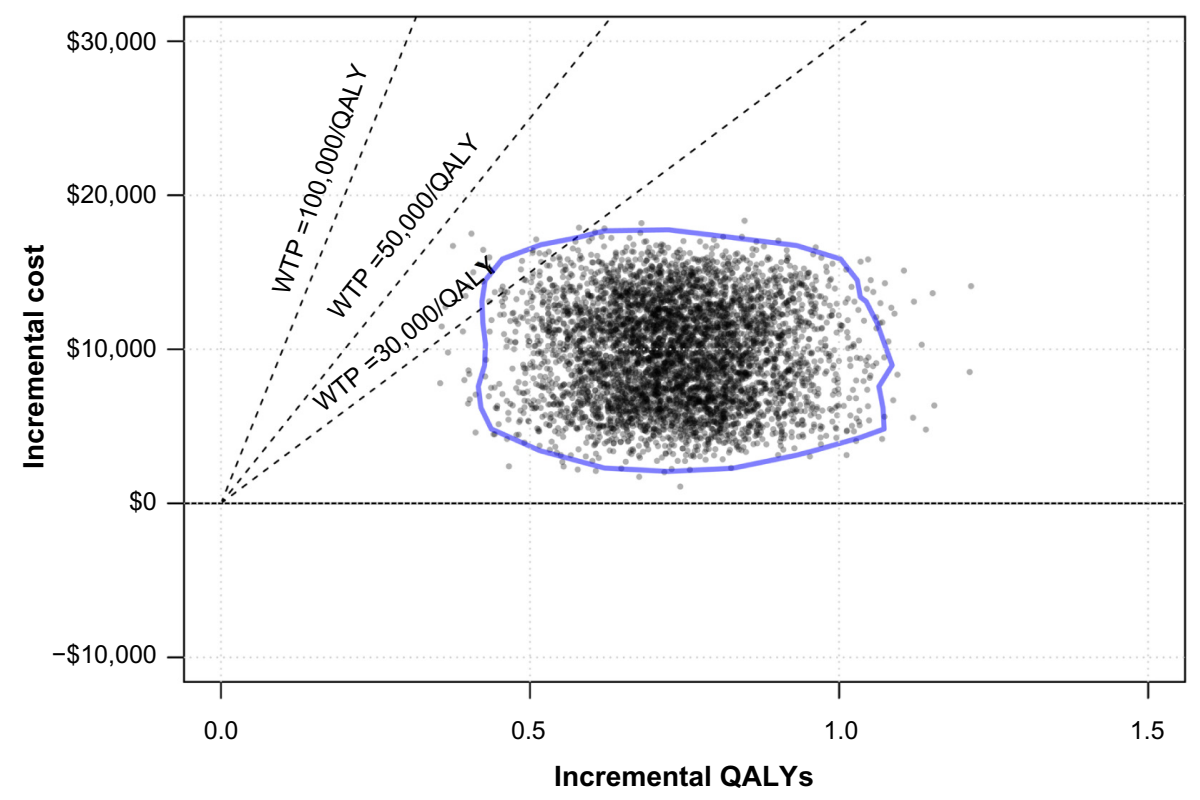

Figure S4 Probabilistic sensitivity analysis of incremental costs and effectiveness for SIJ fusion surgery vs non-surgical treatment over 5-year time horizon.

Notes: Blue circle shows area of $95 \%$ probability based on $2 \mathrm{~d}$ bivariate kernel density estimates. The two dotted lines show willingness-to-pay (WTP) ratios of $\$ 50,000$ and $\$ 30,000$ per QALY. Currency is presented as US dollars.

Abbreviations: SIJ, sacroiliac joint; QALY, quality-adjusted life year.

ClinicoEconomics and Outcomes Research

\section{Dovepress}

\section{Publish your work in this journal}

ClinicoEconomics \& Outcomes Research is an international, peerreviewed open-access journal focusing on Health Technology Assessment, Pharmacoeconomics and Outcomes Research in the areas of diagnosis, medical devices, and clinical, surgical and pharmacological intervention. The economic impact of health policy and health systems organization also constitute important areas of coverage. The manuscript management system is completely online and includes a very quick and fair peer-review system, which is all easy to use. Visit http://www.dovepress.com/testimonials.php to read real quotes from published authors.

Submit your manuscript here: http://www.dovepress.com/clinicoeconomics-and-outcomes-research-journal 